\title{
Engagement with genetic discrimination: concerns and experiences in the context of Huntington disease
}

\author{
Yvonne Bombard ${ }^{1}$, Elizabeth Penziner ${ }^{2}$, Oksana Suchowersky ${ }^{3}$, Mark Guttman ${ }^{4}$, \\ Jane S Paulsen ${ }^{2}$, Joan L Bottorff ${ }^{5}$ and Michael R Hayden ${ }^{*, 1}$
}

\begin{abstract}
${ }^{1}$ Department of Medical Genetics, Centre for Molecular Medicine and Therapeutics, Child and Family Research Institute, University of British Columbia, Vancouver, British Columbia, Canada; ${ }^{2}$ Departments of Psychiatry, Neurology, Psychology and Neurosciences, University of Iowa, Iowa City, IA, USA; ${ }^{3}$ Departments of Medical Genetics and Clinical Neurosciences, University of Calgary, Calgary, Alberta, Canada; ${ }^{4}$ Departments of Medicine and Psychiatry, Centre for Addiction and Mental Health, University of Toronto, Toronto, Ontario, Canada; ${ }^{5}$ Faculty of Health and Social Development, University of British Columbia Okanagan, Kelowna, British Columbia, Canada
\end{abstract}

It has been over 20 years since the inception of predictive testing for Huntington disease (HD), yet the social implications of knowing one's genetic risk for HD have not been fully explored. Genetic discrimination (GD) is a potential risk associated with predictive testing. Although anecdotal reports of GD have been documented, there is a paucity of research on the nature and experiences of GD in the context of HD. The purpose of this study was to describe the concerns and experiences of GD in the HD community. Semistructured interviews were conducted with 45 genetically tested and 10 untested individuals and analyzed using grounded theory methods. Our findings demonstrate that a majority of individuals were concerned about (37/55) and experienced GD (32/55) across a variety of contexts that extend beyond the traditionally examined contexts of insurance and employment to include family, social, government, and health-care domains. We describe a process of engagement with GD in which individuals formed meaningful interpretations of GD and personalized its risk and consequences in their lives. Our findings provide an insight into some of the specific processes and factors influencing engagement with GD. These results help identify areas where more education and support is needed and provide direction to genetic professionals supporting their clients as they confront issues of GD and genetic testing.

European Journal of Human Genetics (2008) 16, 279-289; doi:10.1038/sj.ejhg.5201937; published online 24 October 2007

Keywords: genetic discrimination; Huntington disease; predictive testing; stigma

\section{Introduction}

Huntington disease (HD) is a degenerative neuropsychiatric disorder that usually presents in mid-life as a triad of cognitive, psychiatric and movement disturbances. It is inherited in an autosomal dominant manner and is caused

${ }^{*}$ Correspondence: Dr MR Hayden, Department of Medical Genetics, Centre for Molecular Medicine and Therapeutics, Child and Family Research Institute, University of British Columbia, 950 West 28th Avenue, Vancouver, British Columbia, Canada V5Z $4 \mathrm{H} 4$.

Tel: +1 1604875 3535; Fax: + 1604875 3819; E-mail: mrh@cmmt.ubc.ca Received 6 April 2007; revised 19 September 2007; accepted 20 September 2007; published online 24 October 2007 by a mutation comprising a CAG trinucleotide expansion in the $H D$ gene. ${ }^{1}$ Individuals affected with HD suffer from mood and personality changes, progressive cognitive decline and worsening of the movement disorder, which ends in death approximately 15-20 years from diagnosis. ${ }^{2}$ No therapy is currently available to alter the course of the disease.

The discovery of a polymorphic DNA marker tightly linked to $\mathrm{HD}^{3}$ led to the first predictive test for an adult onset genetic disease in 1986, allowing at-risk individuals to learn with near complete certainty whether or not they have inherited the HD mutation. ${ }^{4}$ Although early surveys 
indicated that predictive testing would be requested by $66-79 \%$ of individuals at risk for $\mathrm{HD}^{5,6}$ worldwide uptake currently ranges between 3 and $24 \%$ among at-risk individuals. ${ }^{7}$ The most frequently cited reasons for declining predictive testing have been the absence of a cure, concerns about coping and the fear of genetic discrimination (GD). ${ }^{8}$

GD refers to the perceived differential treatment of individuals or their family members based on presumed or actual genetic differences rather than physical characteristics. ${ }^{9}$ Although considerable debate surrounds the existence of GD in the context of $\mathrm{HD},{ }^{10}$ there is a paucity of research on the nature and experiences of GD among this community. Reports of GD have been documented among a variety of genetic disease communities. ${ }^{9,11-17}$ The anecdotal report of a teacher in Germany who was deemed unfit to teach only because she was at high risk for HD focused international attention on this issue. ${ }^{10,18}$ Strategies to manage the risk and experiences of GD have been described. ${ }^{19}$ They included 'keeping low' (ie attempts to pass or carry on and keeping results private) as well as preempting, minimizing and confronting GD. These strategies varied depending on the form of the GD experience and the degree to which individuals engage with (or internalize) GD.

The consequences of GD, both for individuals and society, are far-reaching as they have the potential to create significant social, health and economic burdens by limiting opportunities for individuals at genetic risk in a range of contexts. ${ }^{20}$ Given the likelihood that similar tests will become increasingly available for predicting risks for other diseases, exploring the nature of GD in the context of HD will be generally instructive for other disorders. As individuals' strategies for managing GD appeared to vary in terms of how they constructed their experiences, it would be helpful to have a better understanding of their initial reactions to GD (or the risk of GD) and how they make sense of these experiences. The aim of this study was to explore concerns and experiences of GD among asymptomatic individuals from HD families.

\section{Methods}

Qualitative research approaches facilitate the conceptual exploration of otherwise unexplored phenomena ${ }^{21}$ and are also appropriate when the intent of the study is to gain insights into the meaning of experiences from individuals. As such, this study aimed to explore the concept of GD as well as the concerns and experiences of GD. This inquiry was informed by grounded theory, a qualitative research approach typically used to explore basic social processes ${ }^{22}$ based on the theoretical assumptions of symbolic interactionism. ${ }^{23}$ The choice of grounded theory is consistent with the assumption that GD is situated in the social interactions that occur when presumptions or information about genetic status come into play.

\section{Study sample and recruitment}

The approval of the relevant research ethics boards was received to recruit individuals from three genetic and movement disorder clinics in Vancouver, Calgary and Toronto, Canada. To facilitate the exploration of discrimination based on genetic information as opposed to symptoms or disability, only individuals who were not diagnosed with HD were eligible to participate. Symptom status was confirmed with recent neurological assessments at these clinics. Written and verbally recorded informed consent was obtained from all participants.

Thirty-seven individuals who were found to have the HD mutation (HD + ; positive test result) were sampled according to purposive sampling procedures where variation across participant demographic variables was sought (eg age, gender, education and time since genetic testing) and formed the primary sample for this study. Ten people with a family history of HD but who chose not to undergo testing (NT; not tested), as well as eight people who were found not to have the HD mutation (HD-; negative test result), were recruited for the purpose of making theoretical comparisons. Theoretical comparisons are a vital part of discovering the properties and dimensions in the data and enable identification of variations in the developed theory. ${ }^{22}$ Inclusion of these comparison cases provide the opportunity to assess how family history and negative test results influenced concerns and experiences of GD and tested the limits of the proposed theory. Participant recruitment continued until no new themes developed from subsequent interviews. ${ }^{22}$

\section{Data collection}

Data were collected through individual, semistructured, open-ended interviews conducted by telephone $(n=16)$ and in person $(n=39)$. All the interviews were conducted by the first author and lasted $65 \mathrm{~min}$ on average (range: 50-90 min). The interviews were digitally recorded, transcribed verbatim and checked for accuracy. Field notes were maintained to document important contextual and behavioral information.

During the interviews, participants were encouraged to reflect on the following issues: their interpretations of GD, their experiences and concerns for GD, their thoughts on genetic privacy, as well as personal, social and other factors involved in their concerns and experiences of GD. In view of the sensitivity and potential bias introduced with the term discrimination, interviews were conducted using its definition, 'differential treatment,' which enabled participants to reflect on both the positive and negative aspects of learning about their predictive test results or family history of HD. 


\section{Data analysis}

Constant comparison analysis was used to explore the concerns and experiences of GD. Interview transcripts were entered into a software program (NVivo 2, QSR International) to facilitate coding and data retrieval. The way in which the grounded theory analysis was used is described in detail elsewhere. ${ }^{19}$

\section{Results}

\section{Sample characteristics}

The characteristics of the participants in our study are presented in Table 1. The characteristics of our tested sample appear similar to previous reports of Canadian adults who receive predictive testing results for HD. ${ }^{7,24}$ The characteristics of our untested sample appear similar to individuals who choose not to test, although they are more educated. $^{8}$

\section{Concerns and experiences of GD}

In the course of discussions about GD, participants spoke about their concerns and experiences in a pensive manner, yet with a tone of conviction. At times, non-verbal cues such as hand-gesturing and shifting in their seats were evident among some individuals, suggesting some discomfort with this potentially sensitive topic. Although most discussions of their concerns and experiences were fairly detailed, some participants limited their narratives to matter-of-fact statements (eg as in the case of insurance GD), not providing much in the way of feelings or details. In addition to the word 'discrimination', participants frequently used other terms such as 'issues,' 'ramifications' and 'adverse consequences' when referring to GD.

Individuals reported concerns about and experiences of GD in various forms, including increased symptom monitoring, communication changes, a perceived lack of closeness or support as well as pressure regarding reproductive, educational and marriage decisions from relatives. Loss of financial benefits was also linked with GD in the form of insurance rejection and increased premiums, imposed limits to opportunities in the workplace, promotional denials and forced retirement. Perceived differential treatment related to HD familial history and genetic test results were also associated with increased surveillance by employers, experiences of social avoidance and pity as well as perceptions of altered medical advice by health-care

Table 1 Sample characteristics

\begin{tabular}{|c|c|c|c|c|c|c|c|c|}
\hline & \multirow{2}{*}{\multicolumn{2}{|c|}{$\begin{array}{c}\text { Primary sample } \\
\text { Participants with HD } \\
\text { mutation }(\mathrm{n}=37)\end{array}$}} & \multicolumn{4}{|c|}{ Comparison cases } & \multicolumn{2}{|c|}{$\begin{array}{c}\text { Total } \\
(\mathrm{n}=55)\end{array}$} \\
\hline & & & \multicolumn{2}{|c|}{$\begin{array}{l}\text { Participants without HD } \\
\text { mutation }(\mathrm{n}=8)\end{array}$} & \multicolumn{2}{|c|}{$\begin{array}{c}\text { Participants who have not } \\
\text { tested }(\mathrm{n}=10)\end{array}$} & \multirow[b]{2}{*}{$\mathrm{n}$} & \multirow[b]{2}{*}{$\%$} \\
\hline & $\mathrm{n}$ & $\%$ & $\mathrm{n}$ & $\%$ & $\mathrm{n}$ & $\%$ & & \\
\hline \multicolumn{9}{|l|}{ Gender } \\
\hline Female & 23 & 62 & 5 & 63 & 9 & 90 & 37 & 67 \\
\hline Male & 14 & 38 & 3 & 38 & 1 & 10 & 18 & 33 \\
\hline \multicolumn{9}{|l|}{ Marital status } \\
\hline Married/common-law & 23 & 62 & 6 & 75 & 8 & 80 & 37 & 67 \\
\hline Single/separated/divorced/widow & 14 & 38 & 2 & 25 & 2 & 20 & 18 & 33 \\
\hline \multicolumn{9}{|l|}{ Education } \\
\hline Some college and above & 31 & 84 & 8 & 100 & 9 & 90 & 48 & 87 \\
\hline High school and below & 6 & 16 & 0 & 0 & 1 & 10 & 7 & 13 \\
\hline \multicolumn{9}{|l|}{ Employment } \\
\hline Employed & 26 & 70 & 6 & 75 & 10 & 100 & 42 & 76 \\
\hline Unemployed & 11 & 30 & 2 & 25 & 0 & 0 & 13 & 24 \\
\hline \multicolumn{9}{|l|}{ Children } \\
\hline Have children & 27 & 73 & 6 & 75 & 7 & 70 & 40 & 73 \\
\hline Have no children & 10 & 27 & 2 & 25 & 3 & 30 & 15 & 27 \\
\hline \multicolumn{9}{|l|}{ Time since testing } \\
\hline $0-4$ years & 9 & 24 & 2 & 25 & - & - & $11^{a}$ & $41^{a}$ \\
\hline $5-9$ years & 16 & 43 & 1 & 13 & - & - & $17^{a}$ & $63^{a}$ \\
\hline $10-14$ years & 10 & 27 & 3 & 38 & - & - & $13^{a}$ & $48^{a}$ \\
\hline $15-20$ years & 2 & 5 & 2 & 25 & - & - & $4^{a}$ & $15^{a}$ \\
\hline
\end{tabular}

$\mathrm{HD}$, Huntington disease.

${ }^{a}$ Based on tested sample $(n=27)$. 
Table 2 Proportion of concerns and experiences of genetic discrimination ${ }^{a}$

\begin{tabular}{|c|c|c|c|c|c|c|c|c|}
\hline & \multirow{2}{*}{\multicolumn{2}{|c|}{$\begin{array}{c}\text { Primary sample } \\
H D+(\mathrm{n}=37)\end{array}$}} & \multicolumn{4}{|c|}{ Comparison cases } & \multicolumn{2}{|c|}{ Total $(\mathrm{n}=55)$} \\
\hline & & & $H D-$ & $(n=8)$ & $N T$ & $=10)$ & & \\
\hline & $\begin{array}{c}\text { Concerns } \\
\mathrm{n}\end{array}$ & Experiences $\mathrm{n}$ & $\begin{array}{c}\text { Concerns } \\
\mathrm{n}\end{array}$ & $\begin{array}{c}\text { Experiences } \\
\mathrm{n}\end{array}$ & $\begin{array}{c}\text { Concerns } \\
\mathrm{n}\end{array}$ & $\begin{array}{c}\text { Experiences } \\
\mathrm{n}\end{array}$ & $\begin{array}{c}\text { Concerns } \\
\mathrm{n}\end{array}$ & $\begin{array}{c}\text { Experiences } \\
\mathrm{n}\end{array}$ \\
\hline Overall & 28 & 25 & 4 & 5 & 5 & 5 & 37 & 32 \\
\hline Family & 4 & 13 & 0 & 4 & 0 & 1 & 4 & 19 \\
\hline Insurance & 16 & 9 & 2 & 1 & 3 & 4 & 21 & 14 \\
\hline Employment & 19 & 5 & 3 & 3 & 3 & 0 & 25 & 8 \\
\hline Social & 11 & 6 & 1 & 0 & 1 & 1 & 13 & 7 \\
\hline Health Care & 3 & 2 & 0 & 0 & 0 & 0 & 3 & 2 \\
\hline $\begin{array}{l}\text { Government (ie adoption, } \\
\text { blood bank) }\end{array}$ & 0 & 0 & 0 & 0 & 0 & 2 & 0 & 2 \\
\hline
\end{tabular}

${ }^{\mathrm{a}}$ Categories are not mutually exclusive; participants may have spoken about experiences/concerns under various domains.

professionals. Individuals also reported feelings of being 'tainted' by their family history of HD in social and employment situations. A summary of these concerns and experiences is presented in Table 2 .

For all of the participants, GD was not an issue they thought about on a regular basis but one that they considered 'occasionally' when an event sensitized them to the issue. Renee (pseudonyms have been used to protect the identity of participants) (HD-) explained: 'you're not constantly thinking about it every moment and you just kind of get on with life and every now and then, you know, something hits you.' Awareness of GD was precipitated by events that suggested to the participants that having a genetic difference may have consequences.

\section{Awareness events}

Participants became aware of GD through observations of affected relatives' experiences of stigma and discrimination, through information provided by genetic counselors and through their own experiences of GD.

Growing up with a symptomatic family member sensitized participants early to $\mathrm{HD}$ - related stigma and discrimination. Kate $(\mathrm{HD}+)$ recalled the 'ignorance' she experienced when members of the public would react to her affected mother by asking: 'what's wrong with her; she's drunk?' Similar experiences were reported among the other groups. Tanya (HD-) described her frustration with how her symptomatic mother was treated as though she were 'dumb' and a 'homeless person' by those around her, despite efforts to educate others about the disease. Frances (NT) also recalled how her father's neighborhood ostracized him when he began exhibiting the illness, owing to a lack of understanding.

Receiving information about GD constituted the second type of awareness event. Genetic counselors were the primary source of this information for participants who received genetic counseling. For example, being advised by genetic counselors to 'look into' life insurance before proceeding with predictive testing and to be careful about disclosing test results directly highlighted the potential for GD. Participants from all groups also became aware of the potential for GD from questions on insurance applications, reports from social support groups, the HD newsletter and television programs, which highlighted particular cases of GD in the United States.

Personal experiences of differential treatment constituted the third type of awareness event. These experiences were most clearly represented among our primary sample (HD + group) and occurred in five domains: insurance, family, social, health care and employment. Of the 25 individuals who experienced GD, nine described experiences of being treated differently in insurance underwriting, being denied insurance policies and upgrades. Subtle forms of differential treatment in family situations also arose that participants related to their real or assumed genetic status. Thirteen individuals described experiences that included altered patterns of interaction, symptom monitoring and events where they felt their test results were used against them by family members. For example, some participants spoke of their discomfort with the fact that their spouses began watching them 'like a hawk' for symptoms of $\mathrm{HD}$ after learning their test results. In one instance, a single mother recalled an unexpected encounter with GD during legal proceedings where her test results were 'used against' her by her ex-partner as a threat to pursue custody of their daughter.

With respect to their social domain, six participants linked experiences of romantic relationship rejection, social 'shunning' and being treated as having a 'contagious disease' to their new HD genetic status. In the health-care domain, two individuals described altered medical advice following disclosure of their HD genetic status. One believed that the advice she received that her daughter should not have children if genetic tests were positive for HD was insulting. The other was frustrated when her physician attributed her current, unrelated medical issues to her genetic test result for HD and did not manage her symptoms with the attention she felt they deserved. 
The most blatant forms of discrimination were reported to have occurred in the workplace by five participants. The participants believed that the information about their genetic status was directly related to unsuccessful bids to get a promotion, imposition of an unwanted early retirement and increased surveillance by their employers. For example, Michelle, a health-care professional, felt singled out because of her genetic test results when her supervisor requested access to her medical files so that her employers could 'monitor' her for symptoms 'faster, easier than taking [her] word for it.' Awareness events like these prompted individuals to begin a cognitive and emotional process of engagement with GD as a preliminary step toward attending to their feelings of frustration or concern and determining their risk and consequences of GD.

\section{The concept of engagement with GD}

Engagement with GD describes a cognitive and emotional process individuals used to interpret the meaning of GD and personalize its risk and consequences in their lives. The process of engagement is precipitated by awareness events and results in personal formulations of the risk and effects of GD. Engagement with GD provides a framework to understand individuals' perceptions and experiences of GD as well as their reactions to and strategies for GD. Each phase of engagement with GD and factors that influenced this process are described in more detail in the following sections. Examples reflecting differences in the engagement process between the groups are highlighted where appropriate.

\section{States of engagement with GD}

On the basis of differences observed among participants, three broad states with respect to engagement with GD were identified: engaged, disengaged and resisting engagement. The state of engagement with GD was directly influenced by one's genetic status and risk perception for HD. Although all the participants in our study were at risk for HD at some point in their lives (ie they were 'all in the same boat'), the way in which they engaged with GD, either with respect to their family histories or their genetic test results, varied with their genetic status and risk perception for HD. Individuals who chose not to undergo genetic testing (NT) usually thought about their risk for developing $\mathrm{HD}$ with a certain degree of optimism or pessimism. Untested participants who spoke as though they had the HD mutation (pessimistic bias) engaged with GD in similar ways to $\mathrm{HD}+$ participants. In contrast, participants who held an optimistic bias (low perceived risk for HD) normalized their genetic risk for HD, arguing that they are no different than colleagues or members of their social circles who have family members suffering from other common disorders. Anna (NT) alluded to this: 'I'm thinking well, yeah, I'm a potential risk [but] so is the guy next door; he could die of a heart attack tomorrow, you know,'. They did not believe that their family history of HD necessarily set them apart from others. They also maintained a position that they were just as likely not to have the HD mutation as to have it. Hillary (NT) explained: 'I choose to look at it that there's a fifty percent chance that I'm not going to get it and there is no more chance that I will.' Thus, they perceived that their risk for GD is no different than the general public and deflected the need to engage with GD. Hannah asserted: 'I don't go there, I don't think about it... I acknowledge the existence of it and that's about it.' Thus, some untested participants who held an optimistic bias were able to deflect the need to engage with GD and ultimately resisted engagement.

Individuals who underwent genetic testing were required to engage with GD as part of the informed consent process. However, those who learned that they did not have the HD mutation were able to disengage themselves from GD, as they were no longer at risk for HD. They discussed their ability to 'un-attach' themselves from 'the baggage of HD' or 'remove the stigma of the disease' by 'reinforcing' their 'negative' test results to others. After learning of their results, these individuals simply disengaged themselves from GD because they felt that GD was a 'non-issue', as they considered themselves 'normal.'

Ultimately, four groups can be discerned from the categorization of engagement along the dimensions of their risk perception and genetic status for HD: tested individuals who had the HD mutation $(\mathrm{HD}+)$, tested individuals who did not to have the HD mutation (HD-), untested individuals who held a pessimistic bias about their HD risk (NT-P) and untested individuals who held an optimistic bias about their HD risk (NT-O). Essentially, all groups except for the latter engaged with GD (Figure 1). It is important to note, however, that individuals' genetic status for HD and risk perception is not a static state. HDparticipants, for example, spoke about past experiences of stigma and discrimination based on their family history despite the fact that they were in a position to disengage with GD. Likewise, one's risk perception for $\mathrm{HD}$ can presumably fluctuate over time. Categorizing participants along these dimensions, nonetheless, was helpful in illustrating how one's genetic status and risk perception at the time of their particular awareness event influenced the way in which they engaged with GD.

\section{The process of engagement with GD}

Engagement with GD involved two phases. Initially, individuals formed meaningful interpretations of GD by making sense of GD, defining its various forms and validating the threat of GD. In the second phase, individuals personalized GD to determine its risk or consequences for themselves or their families. They did this by conducting a mental survey - taking into account their social, financial, employment or familial circumstances as a way of assessing their potential for GD or of 


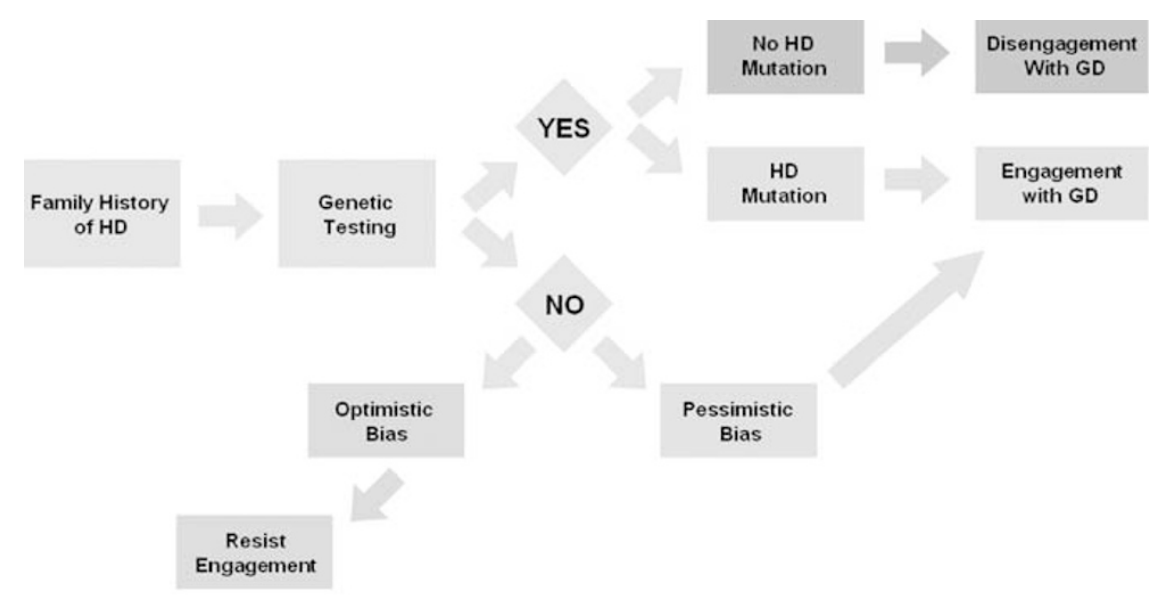

AWARENESS EVENTS

Figure 1 States of engagement with GD in relation to genetic status and risk perception for HD. HD, Huntington disease; GD, genetic discrimination.

understanding the consequence of a particular GD experience. Emotional reactions often ensued in the course of engagement, which included feelings of concern, irritation, anger, frustration or indifference.

\section{Forming meaningful interpretations of GD}

The phase of forming meaningful interpretations of GD occurred when individuals began to reflect on what they learned or experienced that raised the issue of GD. Three themes in the data describe the cognitive strategies used: assigning meaning, defining forms of GD and validating the threat of GD.

Assigning meaning As most participants attempted to make sense of awareness events, they did not immediately label them as 'genetic discrimination.' Rather, they associated GD with notions of 'exclusion,' 'restricting access,' 'disallowing,' 'being prevented from doing something,' 'isolation' and 'unfair treatment.' For the participants who engaged with GD, differential treatment consisted of both positive and negative forms, but discrimination was regarded as a negative, 'stronger' form of differential treatment.

Participants invoked human rights issues and shared strong reactions as they attempted to makes sense of negative forms of differential treatment. Scott $(\mathrm{HD}+)$ deemed employment GD as 'totally unfair, illegal, and inappropriate, a travesty which we as a society shouldn't accept.' Kerry (HD-) interpreted insurance and social GD as 'horrible negative treatment, having something taken away based on a birth defect.' Participants likened differential treatment related to genetic status to other types of discrimination based on ethnicity or religion, which were similarly 'unethical.' Patrick $(\mathrm{HD}+)$, for example, explained why his GD experiences were a 'definite Charter [of Rights and Freedoms] issue:'

From a legislative point of view, discrimination based on genetic testing... is no different than discriminating against somebody who's a visible minority or [has] a handicap, you know, because right now you can't, under the charter [of Rights and Freedoms], you can't discriminate against people because of a disability, right? So do I have a disability? Right now, today, no, but I'm being discriminated against.

Prejudice and stigma were elements highly intertwined in participants' interpretations of GD. Hillary (NT-P) explained the moral underpinnings of GD when she asserted, 'They're disallowing people for things that have not affected them yet. Yeah, I think that's absolutely prejudicial.' Kerry (HD-) recounted her thoughts about GD before receiving her test results and described these consequences as 'stigmatizing:'

I get energy from people. So to take that away from me, you're draining me and by stigmatizing me, isolating me, singling me out, you are taking that away from me. So for me that would be, that would be a very horrible thing, I would hate that.

Defining forms of GD Participants' interpretations of GD also included defining the various forms of differential treatment related to genetic status: actual or perceived and interpersonal or institutional forms. Actual GD was characterized by participants as having 'proof' of a GD event, whereas perceived GD was associated with the absence of objective evidence. Patrick $(\mathrm{HD}+)$ used this distinction to conceptualize his GD experiences of being 
required to pay increased life insurance premiums and having been denied a promotion.

It's actual [discrimination] because the insurance company is asking have you been tested for Huntington's disease or has any family member been tested for Huntington's. That's not perceived. That's actual because it's written on... the [insurance] forms. So perceived discrimination is... where I think it impacted in a significant way the decision of me not getting that position, [but] I could be completely wrong.

Some individuals also drew a distinction between institutional and interpersonal GD. Interpersonal forms of GD, underpinned by 'personal interaction' and 'emotions,' occurred in family and social environments. This contrasted with institutional forms of GD, such as in the workplace, courts, adoption, health care or insurance industry, which lacked an emotional basis.

Validating the threat of GD Concepts of rights, fairness and rationality were used by participants to validate GD. Participants' interpretations of GD were founded upon a perception that genetic information is inherently special. Individuals regarded this information as 'personal' and, therefore, it did not need to be shared. Accordingly, participants believed that insurance companies and other third parties had 'no right' to their genetic information and questioned the fairness of denying or terminating insurance coverage on the basis of predictive test results.

Others who focused on the 'unfairness' of being treated differently by insurers thought that they should not be penalized for things over which they have no control. As one participant explained, 'It's the luck of the draw and unfortunately I've got the defective gene so it's not my fault that I got it [HD mutation] but you [insurer] should cover me.' Paul (HD-) believed that using genetic information in hiring practices would be 'unfair' and have widespread consequences:

There's so many tests for genetics these days and would an employer... have the right then not to hire you based upon that?... I think probably because testing has got so specific and accurate now to identify these things, it's [GD] probably unfair because... it could affect thousands of people too, you know, look at the number of identified genetic diseases, that could affect an awful lot of people.

\section{Personalizing the risk for and consequences of GD}

The second phase of engagement with GD included participants' efforts to determine how GD may affect them or their families as well as their emotional responses to GD. Participants conducted a mental survey of their personal circumstances to predict or imagine the consequences of having a genetic difference. Although some participants engaged with GD to attend to their feelings of concern or anxiety, others described concern or indifference as a result of personalizing the risks and consequences of GD.

Conducting a mental survey Participants used a 'factoring in' process in which they systematically reviewed their current and future circumstances to make the best possible assessment of their potential for GD. They placed emphasis on those contexts potentially affected by their genetic status, such as insurance policies, workplace environment and interpersonal relationships. Patricia $(\mathrm{HD}+)$ recalled explicitly surveying her current circumstances: 'I took my time to stop and think about this whole thing. The people you work for and your family, you know your associates... especially insurance.' She explained how her 'factoring in' process took a few months, 'I wanted to cover all my bases and do research and find out what coverage I had, what benefits I had, what I would lose if I told anybody.' However, uncertainties about possible reactions by others often complicated this mental survey. In thinking about his potential for GD at work, Wesley $(\mathrm{HD}+)$, a married father and corporate executive, characterized his efforts to determine his personal risk for GD as a 'struggle.' He said:

I struggled a lot... I thought about... taking on a new job which I've just recently done... should I tell somebody that I have this condition that in five years time might affect me and all of that and I said, you know what: 'no.'

Similarly, Kerry (HD-) explained her 'factoring in' process before predictive testing and described the consequences of GD as 'horrible:'

I'd thought about insurance and I knew... that I would be at risk, that my job would be at risk that my ability to get insurance would be at risk which would, in my view, would put my family at risk if I couldn't be insured and that was a horrible, horrible feeling just knowing that, because you're treated, you're treated differently if you have this [HD mutation].'

In conducting this mental survey, participants relied upon their experience. Individuals sometimes 'factored in' their experiences of public reaction to other diseases in personalizing their risk for GD. Brendan (HD+) considered how lack of public understanding about HIV/AIDS affected the way people with the disease were treated to support his concerns about GD. He recalled:

Ignorance breeds fear as people do not understand something, then they fear it and if they fear it, then, yes, they're going to treat you differently. I mean a perfect example of that is, is people with AIDS and how that was handled when we didn't understand how that disease was transmitted from person to person. 
Individuals reflected on both positive and negative experiences in their assessment of their potential for GD. Although increased support, empathy and acceptance were recognized as positive experiences following predictive testing, participants dwelt on the impact of negative experiences.

Reacting to the risk and consequences of GD Personalizing GD involved a range of emotional reactions that informed the way individuals internalized the consequences of GD. These included feelings of concern, irritation, anger, frustration and indifference. Concern, however, was the predominant emotion expressed by participants for themselves and, particularly, for their children. Ethan's $(\mathrm{HD}+)$ concern about the possible implications of his genetic test result for his children are reflected in the following quote: 'I suppose the possibility of people who do understand the genetics of it are going to look at my three kids and say, 'There's one in half of them right there, wonder which ones?'

The nature of concern for GD was wide ranging but centered on a feeling of vulnerability. Rachel's $(\mathrm{HD}+)$ sentiments of employment insecurity were typical:

Any mistakes that I make or anything might be blamed on that or you know might be 'Oh well, you know, it's because she's got that gene'... I think it could be used as a you know as a reason or an excuse to not promote me further if an opportunity like that were to arise, you know, and worrying, you know well, 'Is it safe to give that job to her because you know, you know she might not be all there?'

Similarly, Paul (HD-) recalled feeling vulnerable because of his HD family history:

There was never any chance then [before testing] of changing [jobs] because I felt if I went to another employer that to give them that information [family history of HD], there's a lot of issues over... [and] I wasn't willing to take a chance at a secure job.

In the social context, individuals were concerned about: being 'looked at differently,' being judged or socially rejected and bearing the brunt of 'adverse reactions.' Brendan's $(\mathrm{HD}+)$ cautious approach in social settings reflects his concern for being stigmatized:

Huntington's is something that I would be concerned to just blurt out in a social setting because it would change the way people think... I mean that would change things immensely... that would absolutely change how people deal with me.

Individuals also indicated concern for future isolation and decline of current levels of family support and altered medical care. Rachel, for example, was apprehensive about how knowledge of her HD status could bias her physician's clinical assessments:

But even in my doctor's... I'd rather that, you know, that if he at some point needs to determine that I'm symptomatic or not, that he's making that from a purely clinical point of view.

Indifference usually ensued when individuals determined that they were protected in some way from the effects of GD. Zara $(\mathrm{HD}+)$ explained why she was indifferent:
Afterwards I felt well, I really don't give a damn because I'm covered. You know, where I worked, the people are good. I'm not going to lose any pay. I'm not going to lose any of my benefits. My Blue Cross or hospitalization coverage is maintained through- out... so I don't have to worry.

Factors influencing the degree of engagement with GD Individuals engaged with GD to different degrees depending on various factors, which served to facilitate or impede the process. Individuals who engaged with GD to a greater extent acknowledged the relevance of GD and directly attended to its potential or experience in an active manner. Frequently, individuals highly engaged with GD described strong emotional reactions. In contrast, participants who engaged with GD to a lesser extent did not actively reflect upon the experience or its potential and neither did they make strong connections between their experiences and GD. Two factors had a major influence on the degree of engagement with GD: stage of life and the nature of the awareness events.

Stage of life Individuals' engagement with GD fluctuated over time as their lives and family circumstances evolved. Participants in the earlier stages of building their lives, with young families, entering new careers and still building relationships, for example, engaged actively with GD. In contrast, those for whom most life building events occurred before learning of their genetic status or risk for HD perceived GD as less relevant, as reproductive, financial and career decisions were already set in place.

Nature of the awareness events Participants who became aware of GD in a direct manner engaged with GD to a greater extent. During genetic counseling sessions, for example, patients are routinely prompted to consider the psychosocial impact of predictive test results. Warnings received from genetic counselors during predictive testing sessions raised alarms for Zara $(\mathrm{HD}+)$ :

You get so many warnings when you're in counseling. They tell you don't disclose this to outside members of the family, don't disclose this to your 
insurance, don't disclose this to your employer, don't disclose it to so many areas, you know, and that's why I was concerned because I thought ooh what am I going to do?

In contrast, those who became aware of GD through an indirect or emotionally neutral event, such as through information obtained in a newsletter or support group, engaged to a lesser degree with GD.

\section{Discussion}

Our findings demonstrate that a majority of genetically tested and untested individuals in this HD sample are concerned about and experience GD across a wide variety of contexts. This study introduces the psychosocial process of engagement with GD and provides insight into at-risk persons' perceptions of what constitutes GD.

While our results support previous surveys that explored the existence of GD in the domains of insurance and employment, ${ }^{11-13,15,16}$ our study is the first to provide a detailed description of the concerns and experiences of GD in the HD population, and at the same time to extend the context of GD to include family, social, government and health-care settings. Although changes in family relationships have previously been noted to occur after predictive testing for $\mathrm{HD}^{25}$ this report highlights the fact that individuals link disrupted interactions and patterns of behavior within the family with discrimination. Although discriminatory experiences have not been typically linked to family interactions, this form of GD needs to be considered along with more obvious forms of GD related to insurance and employment.

Most importantly, the study offers an insight into the cognitive and emotional process of engagement with GD aimed at interpreting the meaning of GD and personalizing its risk and consequences. Although other studies indicate that patients learn about GD from news media ${ }^{15,17}$ as well as through their own experiences, ${ }^{26}$ the majority of participants in our study became aware of GD through interactions with genetic counselors. Indeed, in a study of 25 US genetic counselors, 96\% routinely discuss GD in cancer genetics. ${ }^{27}$ An inherent tension exists, however, where, in the process of informing their clients of the potential risks and benefits of genetic testing, genetic professionals may be instilling an unconfirmed perception that GD exists or is widespread. Coupling the provision of information about GD with opportunities for clients to discuss concerns about and past experiences with GD is likely to be helpful in supporting the process of personalizing the factual information presented about GD and identifying strategies to minimize or manage the consequences of GD. ${ }^{19}$ The framework of engagement with GD provides clinicians with a helpful tool to understand and contextualize clients' experiences and may help identify areas where more education and support is needed.

Our findings suggest that individuals regard GD in relation to HD as a basic human rights issue grounded in concepts of privacy, stigma and prejudice. Included in individuals' interpretations of GD were taxonomies and validations that resonate closely with others' conceptualizations based on rationality and social acceptability. ${ }^{28-30}$ Many of our participants reasoned that increasing life insurance premiums is a form of rational and legal discrimination, yet it remains socially unacceptable. This particular discord lies in the balance of whether one considers life insurance a commercial good or a social right. ${ }^{31}$ In a cultural context where universal health care is considered a social right, one may question the existence of equality when access to social goods such as mortgage insurance and small business loans rely increasingly on life insurance eligibility. Given our findings of life insurance and promotional denials, social avoidance and altered medical advice, it appears that opportunities are indeed being limited for these individuals. Thus, former warnings of a looming 'genetic underclass' ${ }^{9}$ may become a real risk.

Engagement as the overarching concept in explaining how individuals interpreted and personalized GD in this study is supported by recent studies developed in relation to genetic risk for HD and hereditary nonpolyposis colon cancer (HNPCC). ${ }^{32,33}$ Although research by McAllister (2002, 2003) and Taylor (2005) contribute important conceptual understanding about the process of engagement in the context of genetics, their conclusions did not serve as theoretical frameworks for the present study. Taylor's (2005) use of the concept of engagement to describe varying degrees of openness and involvement in HD genetic test decision making, observed among at-risk individuals, is not directly related to this study. In her insightful contribution, McAllister's (2002) theory of engagement in relation to genetic risk for HNPCC is based on findings that the degree of cognitive and emotional involvement with individuals' risk for cancer varied from partial to intense over time with the unfolding of critical events in family life. ${ }^{33}$ McAllister's theory of engagement and the engagement with GD theory proposed in this study both involve cognitive and emotional processes, which are precipitated by critical events (life events in relation to engagement with genetic risk, and awareness events in relation to engagement with GD). Likewise, the degree of engagement with cancer risk and GD influences approaches, reactions ${ }^{33}$ as well as strategies ${ }^{19}$ regarding one's risk for genetic risk or GD, respectively. The relationship between engagement with GD and risk perception is also similar to that described by McAllister (2003), with individuals' beliefs about carrier status being linked to their engagement with genetic risk. ${ }^{34}$ Although McAllister's theory did not suggest a direction of the causal link between engagement status and beliefs about carrier status, 
the results of the present study suggest that pessimistic biases toward being an HD carrier promoted engagement while optimistic biases toward not carrying the HD mutation hindered engagement, at least within the context of GD.

There are also important distinctions in the contexts and concepts of these theories. McAllister's (2002) theory of engagement related to genetic risk was developed in the context of studying individuals at $50 \%$ risk of carrying the HNPCC mutation before and after undergoing predictive testing. However, the theory of engagement with GD is based on data provided by genetically tested as well as untested individuals from $\mathrm{HD}$ families and refers to engagement with genetic discrimination. The contexts of HD and HNPCC are notably different in the degree of validity of the test results as well as the nature, penetrance and management of the diseases.

There are also important differences between the concepts of genetic risk and GD. Genetic risk for a future disease presents individuals with information about their personal susceptibility and the challenge of understanding and assimilating this information into their self-image. Although this experience is influenced by emotions ${ }^{35}$ and family contexts, ${ }^{33,36}$ the focus is on the way that risk information shapes individual lives. GD, on the contrary, is grounded in social interactions and relationships and requires individuals to make sense of others' reactions and their own responses to them. Ultimately, one may view engagement with genetic risk as a necessary step toward engagement with GD: individuals may engage with disease risk without ever engaging with GD. Our findings provide further support for McAllister's (2002) theory of engagement and extend the theory to the context of HD and GD. Clearly, engagement appears to be an important concept that requires further exploration and development in other contexts.

There were several limitations in this study that should be considered in the interpretation of our findings. First and foremost, participants who take part in research studies may be a self-selected group ${ }^{37}$ that differs from individuals who decline to participate in terms of their perspectives and experiences of GD. Given that GD is one of the reasons individuals at risk for HD do not participate in predictive testing, ${ }^{8}$ it is possible that we have not fully captured at-risk persons' experiences and concerns for discrimination. As a consequence of our sampling and time frame for recruitment, only one man was available and volunteered to participate in our study. This artifact may support previous suggestions that men can have difficulty in accepting implications of being at risk and cope by using denial. ${ }^{38}$ In addition, because the sample consisted of individuals from the HD community, the study findings may not necessarily apply to other genetic and non-genetic populations. However, with GD cited as one of the main reasons against pursuing predictive testing for $\mathrm{HD}$, indivi- duals from the HD community may be a well-suited population in which to explore these issues. These data are based on self-reports, which rely on individuals' perception of the events that occurred and how they felt they were treated on the basis of their genetic status. In counseling, however, it is the clients' perceptions that are important, and thus these findings provide counselors a framework to understand and contextualize the experiences and concerns that clients share with them. It is also acknowledged that the data were based on experiences from a Canadian sample whose concerns and experiences may not apply to other populations where health-care funding is privatized.

In conclusion, this qualitative study focused on the concerns and experiences of GD, which were grounded in the experience of HD families, and may provide a useful framework for understanding individuals' concerns, experiences and management of GD in other contexts. These results help identify areas where more education and support is needed and provide direction to counselors supporting their clients as they struggle with issues of GD and genetic testing.

\section{Acknowledgements}

We express our gratitude to the families who participated in this study. Without their generosity, this research would have not been possible. We also kindly acknowledge Lynn Raymond, Mary Lou Nicolson Klimek, Joji Decolongon, Christine Giambattista and Janet Williams for their support and guidance of this study. We thank the members of the Hayden laboratory for insightful discussions and critical reading of this paper. We are also thankful to the reviewers whose in-depth comments have significantly improved our paper. Funding for this project was received from the Canadian Institutes of Health Research (CIHR) to Michael Hayden and Joan Bottorff. Supplemental funding was also received from the National Institutes of Health, National Institute of Neurological Disorders and Stroke awarded to Jane Paulsen (number 3 R01 NS040068). Yvonne Bombard is funded by CIHR and the Michael Smith Foundation for Health Research/Child and Family Research Institute. Joan Bottorff is a recipient of a UBC Distinguished Scholar Award. Michael Hayden is a University Killam Professor and holds a Canada Research Chair in Human Genetics and Molecular Medicine.

\section{References}

1 MacDonald ME, Ambrose CM, Duyao MP et al: A novel gene containing a trinucleotide repeat that is expanded and unstable on Huntington's disease chromosomes. Cell 1993; 72: 971-983.

2 Hayden MR: Huntington's Chorea. New York: Springer-Verlag, 1981.

3 Gusella JF, Wexler NS, Conneally PM et al: A polymorphic DNA marker genetically linked to Huntington's disease. Nature 1983; 306: $234-238$.

4 Hayden MR, Bloch M, Fahy M: Predictive testing for Huntington's disease using linked DNA markers. N Engl J Med 1988; 319: $583-584$.

5 Mastromauro C, Myers RH, Berkman B: Attitudes toward Presymptomatic testing in Huntington disease. Am J Med Genet 1987; 26: 271-282. 
6 Kessler S, Field T, Worth L, Mosbarger H: Attitudes of persons at risk for Huntington disease toward predictive testing. Am J Med Genet 1987; 26: 259-270.

7 Creighton S, Almqvist EW, MacGregor D et al: Predictive, prenatal and diagnostic genetic testing for Huntington's disease: the experience in Canada from 1987 to 2000. Clin Genet 2003; 63: $462-475$.

8 Quaid KA, Morris M: Reluctance to undergo predictive testing: the case of Huntington disease. Am J Med Genet 1993; 45: 41-45.

9 Billings PR, Kohn MA, de Cuevas M, Beckwith J, Alper JS, Natowicz MR: Discrimination as a consequence of genetic testing. Am J Hum Genet 1992; 50: 476-482.

10 Harper PS, Gevers S, de Wert G, Creighton S, Bombard Y, Hayden MR: Genetic testing and Huntington's disease: issues of employment. Lancet Neurol 2004; 3: 249-252.

11 Low L, King S, Wilkie T: Genetic discrimination in life insurance: empirical evidence from a cross sectional survey of genetic support groups in the United Kingdom. BMJ 1998; 317: 1632-1635.

12 Lapham EV, Kozma C, Weiss JO: Genetic discrimination: perspectives of consumers. Science 1996; 274: 621-624.

13 Geller LN, Alper JS, Billings PR, Barash CI, Beckwith J, Natowicz MR: Individual, family, and societal dimensions of genetic discrimination: a case study analysis. Sci Eng Ethics 1996; 2: 71-88.

14 Alper JS, Geller LN, Barash CI, Billings PR, Laden V, Natowicz MR: Genetic discrimination and screening for hemochromatosis. J Public Health Policy 1994; 15: 345-358.

15 Apse KA, Biesecker BB, Giardiello FM, Fuller BP, Bernhardt BA: Perceptions of genetic discrimination among at-risk relatives of colorectal cancer patients. Genet Med 2004; 6: 510-516.

16 Armstrong K, Weber B, FitzGerald G et al: Life insurance and breast cancer risk assessment: adverse selection, genetic testing decisions, and discrimination. Am J Med Genet 2003; 120A: 359-364.

17 Hall MA, McEwen JE, Barton JC et al: Concerns in a primary care population about genetic discrimination by insurers. Genet Med 2005; 7: 311-316.

18 Burgermeister J: Teacher was refused job because relatives have Huntington's disease. BMJ 2003; 327: 827.

19 Bombard Y, Penziner E, Decolongon J et al: Managing genetic discrimination: strategies used by individuals found to have the Huntington disease mutation. Clin Genet 2007; 71: 220-231.

20 Otlowski MF, Taylor SD, Barlow-Stewart KK: Genetic discrimination: too few data. Eur J Hum Genet 2003; 11: 1-2.

21 Morse JM, Mitcham C, Hupcey JE, Tason MC: Criteria for concept evaluation. J Adv Nurs 1996; 24: 385-390.

22 Strauss A, Corbin J: Basics of Qualitative Research: Techniques and Procedures for Developing Grounded Theory, 2nd edn. Thousand Oaks, CA: Sage Publications, 1998.
23 Blumer H: Symbolic Interactionism. Perspective and Method. New Jersey: Prentice-Hall, 1969.

24 Bloch M, Fahy M, Fox S, Hayden MR: Predictive testing for Huntington disease: II. Demographic characteristics, life-style patterns, attitudes, and psychosocial assessments of the first fiftyone test candidates. Am J Med Genet 1989; 32: 217-224.

25 Sobel SK, Cowan DB: Impact of genetic testing for Huntington disease on the family system. Am J Med Genet 2000; 90: 49-59.

26 Hall MA, Rich SS: Genetic privacy laws and patients' fear of discrimination by health insurers: the view from genetic counselors. J Law Med Ethics 2000; 28: 245-257.

27 Pfeffer NL, McCarthy Veach P, LeRoy BL: An investigation of genetic counselors' discussion of genetic discrimination with cancer risk patients. J Genet Counsel 2003; 12: 419-438.

28 Taylor SD, Otlowski MF, Barlow-Stewart KK, Treloar SA, Stranger $\mathrm{M}$, Chenoweth $\mathrm{K}$ : Investigating genetic discrimination in Australia: opportunities and challenges in the early stages. New Genet Soc 2004; 23: 225-239.

29 Otlowski M: Exploring the concept of genetic discrimination. J Bioeth Inq 2005; 2: 165-176.

30 Rothstein MA, Anderlik MR: What is genetic discrimination, and when and how can it be prevented? Genetics in Medicine 2001; 3: 354-358.

31 Lemmens T: Selective justice, genetic discrimination, and insurance: should we single out genes in our laws? McGill Law J 2000; 45: 347-412.

32 Taylor SD: Predictive genetic test decisions for Huntington's disease: elucidating the test/no-test dichotomy. J Health Psychol 2005; 10: 597-612.

33 McAllister M: Predictive genetic testing and beyond: a theory of engagement. J Health Psychol 2002; 7: 491-508.

34 McAllister M: Personal theories of inheritance, coping strategies, risk perception and engagement in hereditary non-polyposis colon cancer families offered genetic testing. Clin Genet 2003; 64: 179-189.

35 Klein WM, Stefanek ME: Cancer risk elicitation and communication: lessons from the psychology of risk perception. CA Cancer I Clin 2007; 57: 147-167.

36 Cox SM, McKellin W: 'There's this thing in our family': predictive testing and the construction of risk for Huntington disease. Sociol Health Illn 1999; 21: 622-646.

37 Codori AM, Hanson R, Brandt J: Self-selection in predictive testing for Huntington's disease. Am J Med Genet 1994; 54: $167-173$.

38 Maat-Kievit A, Vegter-van der Vlis M, Zoeteweij M, Losekoot M, van Haeringen A, Roos R: Paradox of a better test for Huntington's disease. J Neurol Neurosurg Psychiatry 2000; 69: 579-583. 